\title{
Identification and Production of Beauvericin by Fusarium subglutinansand F. sacchari from Sugarcane
}

\author{
AeshahMhana Mohammed', \\ https://orcid.org/0000-0002-8001-4175
}

Laith Khalil Tawfeeq Al-Ani ${ }^{2,3^{*}}$
https://orcid.org/0000-0001-5138-0224

1 University of Baghdad,, College of Education for pure science (Ibn al-Haytham), Department of Chemistry, Baghdad, Iraq; 2University of Baghdad, College of Agriculture Engineering Science, Department of Plant Protection, Baghdad, Iraq; ${ }^{3}$ Universiti Sains Malaysia, School of Biology Science, Minden, Pulau Pinang, Malaysia.

Editor-in-Chief:Alexandre Rasi Aoki

Associate Editor:Acácio Antonio Ferreira Zielinski

Received: 2020.03.08; Accepted: 2021.02.24

*Correspondence: cmv_virus2002@yahoo.com (L.K.T.A.A.).

\section{HIGHLIGHTS}

- Isolation two species of pathogens Fusarium from sugarcane.

- Identification the difference in morphological characterization between two species of Fusarium.

- Determination the ability of pathogens Fusarium to produce mycotoxin Beauvericin.

- Determination of the toxicity Beauvericin on the brine shrimp.

Abstract: Fusarium is producing several important mycotoxins including beauvericin (BEA). Two species of Fusarium viz. F. subglutinans and $F$. sacchari cause the Pokkahboeng disease of sugarcane. The studies on the occurrence and toxicity of BEA are scarce. Therefore, this study aimed to identify the isolates of Fusarium and detect their ability to produce BEA. The toxicity of BEA was also tested on brine shrimp Artemia salina. Many isolates of Fusarium were isolated from the infected plants of sugarcane in Malaysia. We identified the species of Fusarium according to their morphological characteristics. The capability of Fusarium isolates for producing the BEA was estimated by using a thin layer chromatography. The toxicity bioassay of BEA was conducted on the brine shrimp larvae. The results were identified on $F$. subglutinans and $F$. sacchari in 55 isolates of Fusarium. All isolates demonstrated the ability to produce BEA. Interestingly, BEA exhibited variation in toxicity between low toxic to very higher toxicity $100 \%$. $F$. subglutinans and $F$. sacchari were able to produce BEA and possibly BEA may be causing toxicity in the host tissue and may be acting as a potential pathogenicity factor. Therefore, we consider BEA as an interesting factor in determining the virulence of fusarium isolate.

Keyword: Fusarium; F. sacchari;F. subglutinans; Beauvericin; Brine shrimp; mycotoxin. 


\section{INTRODUCTION}

Sugarcane is one of the top ten food crops in the world and an important economic crop in many tropical countries [1]. Sugarcane is infested with many plant pathogens including fungi, bacteria, and viruses as well as, insect pests. The genus Fusarium is one of the most devastating plant pathogens producing several mycotoxins [2]. Two species of Fusarium including $F$. subglutinans and $F$. sacchariare well reported to cause Pokkahboeng disease of sugarcane. Fusarium species are able to produce numerous phytotoxins and mycotoxins that could be causing major diseases in humans, animals, and plants [3-5]. Mycotoxins were produced by Fusarium species and other fungi comprising moniliformin, fusaproliferin, fusarins, butenolides, beauvericin, enniatins, and fusaric acid, etc [6-10]. One of interesting mycotoxins is a beauvericin affecting for health of animals and human due to this toxin is more common contaminant for grains after infection with Fusarium [10-11].

Beauvericin (BEA) is a bioactive cyclodepsipeptide that contains three of $\mathrm{N}$-methyl-L-phenylalanyl and D-a-hydroxy-isovaleryl [12]. It was first isolated from entomopathogenic fungi Beauveriabassiana[13-14]. However, the first detected BEA of Fusarium species was by Gupta and coauthors [15]. It is limiting data on the occurrence and toxicity of BEA compared with other mycotoxins. BEA was considered as insecticidal and phytotoxic that exhibited several biological properties [15], antibacterial [16], as well as, showing cytotoxicity towards cell lines from invertebrates, animals and human [17]. The methods for the detection of mycotoxins include gas chromatography (GC), GC-MS, enzyme-linked immunosorbent assay (ELISA), high performance liquid chromatography (HPLC), matrix-assisted laser desorption ionization-time-of-flight mass spectrometry (MALDI-TOF/TOF), liquid chromatography-tandem mass spectrometry (LC-MS/MS), and tinlayer chromatography (TLC) [18-21]. TLC is using a qualitative screening method that assayed many mycotoxins [22].

Several methods have been used for determining the toxicity of mycotoxins by bioassay test. Bioassay could test on organisms including microorganisms, insects, aquatic animals, insects, plants, tissue culture, and organ. There are three bioassays systems including brine shrimp, zebrafish, and chicken embryo known to be able to detect more than 10 types of mycotoxins [23]. The popular choice for the bioassay test is brine shrimp according to the high sensitivity to mycotoxin [24-25]. Therefore, the study aims to identify the Fusarium isolates and investigate their ability for producing BEA. Then, the biotoxicity of BEA was determined using brine shrimp (Artemiasalina).

\section{MATERIALS AND METHODS}

\section{Culture of Fusarium isolates from sugarcane}

A total of 55 isolates for Fusarium spp. were reculturedfrom the Fusarium culture collection unit, School of Biology Science, University Sains Malaysia, Penang, Malaysia. These isolates were taxonomically identified in a previous study [26] by using the Fusarium laboratory manual for Leslie and Summerell [2].

\section{Identification of the $\boldsymbol{F}$. subglutinans and $\boldsymbol{F}$. saccharifrom sugarcane}

Morphological characteristics were used to identify $F$. subglutinans and $F$. sacchari isolates to reconfirm their identity from the stock culture. The morphological descriptions were based on Booth [27], Gerlach and Nirenberg [28], Nelson and coauthors [29], Burgess and coauthors [30], Leslie and Summerell [2], and Wijayawardeneand coauthors [31]. To study microscopic characteristics, the isolates cultured onto CLA (Carnation Leaf Agar) for 7 to 10 days [32]. Morphological features observed for identification of Fusarium species:

A. Macroconidia: Presence or absence, overall shape, shapes of apical and basal cell and the number of septa.

B. Microconidia: Presence or absence, shape, and the number of septa.

C. Mesoconidia: Presence or absence.

D. Conidiophores: Presence or absence, monophialides, and polyphialides.

E. Chlamydospores: Presence or absence, mode of formation, and cell wall.

All the characteristics were observed using a light microscope (Olympus model BX-50F4) and photographed using a camera (JVC model KY-F55BE) with an image Analyzer-single image stereogram (SIS) program. For macroscopic characteristics, PDA (Potato Dextrose Agar) was used for observation of 
culture appearances, such as the texture of the colony, colony colour, pigmentations, and growth pattern. Mycelial disc of $6 \mathrm{~mm}$ diameter was plated onto the fresh PDA plate and the growth rates were recorded after 3 days of incubation. The culture appearance of each isolate on PDA was visually assessed after the mycelia were fully grown. The determination of colony colour and pigmentation was based on the colour description in the Methuen handbook of colour chart [33].

\section{Cultivation of fungal isolates for mycotoxin screening}

The Fusarium isolates were transferred to PDA plates and incubated for 7 to 10 days. Corn grits were used as a culture medium to analyses the presence of mycotoxin as it enhances the mycotoxin production. $15 \mathrm{~g}$ of corn grits with $45 \%$ of moisture was autoclaved in $250 \mathrm{ml}$ Erlenmeyer flask. Spore suspension (approx. $1 \times 10^{6}$ spores) of 1-2 week old culture was prepared to inoculate on the autoclaved corn grit. The inoculated corn grit and control (uninoculated corn girt) were incubated in dark at room temperature for 28 days. Control was treated the same except inoculants was substituted with substituted with sterilized double distilled water.

\section{Extraction of Beauvericin (BEA)}

BEA was extracted from 28 days old inoculated corn grit following the procedure of Logriecoand coauthors [34]. $15 \mathrm{~g}$ of corn grits were extracted overnight with $75 \mathrm{ml}$ of acetonitrile, methanol, and water (16:3:1) and grounded in a warring blender for $5 \mathrm{~min}$. The crude extracted was filtered through Whatman no. 4 filter paper that was defatted twice with $25 \mathrm{ml}$ of $\mathrm{n}$-heptane. The bottom layer was evaporated to near dryness at $80^{\circ} \mathrm{C}$ by a rotary evaporator (Buchi 461, Switzerland). The residue was dissolved in $50 \mathrm{ml}$ of a mixture of methanol and water with 1:1 proportion. Extraction was carried out twice using $25 \mathrm{ml}$ of dichloromethane, which was evaporated and re-dissolved in $50 \mathrm{ml}$ mixture of methanol and water with 1:1 proportion. Extraction was carried out twice using $25 \mathrm{ml}$ of dichloromethane. BEA in the dichloromethane was evaporated and re-dissolved in $1 \mathrm{ml}$ of methanol prior to the detection of BEA through TLC. The extracted mycotoxins were stored in a refrigerator.

\section{Detection of Beauvericin (BEA)}

The detection of BEA was carried out by using thin layer chromatography (TLC). TLC is a sensitive method for mixture analysis by separating the compound in the mixture. About 5 to $10 \mu \mathrm{l}$ of extract were spotted onto a $20 \times 20 \mathrm{~cm}$ silica TLC plates (Pre-coated with silica gel 60 F254; E. Merck AG, Darmstadt, Germany) along with the standard of BEA at 200 ppm from Sigma, USA. Plates developed in the solvent system according to Song and coauthors [35] in a mixture of acetic acid, methanol, water (100:5:1). The plate was air-dried and subsequently, the spot on the TLC plate detected by iodine vapour. Retention factor $\left(R_{f}\right)$ values for the standard and samples were measured. The $R_{f}$ values were calculated according to Touchstone [36] and Fessenden and coauthors [37]:

$$
\mathrm{R}_{\mathrm{f}}=\frac{\text { Distance travelled by the compound }(\mathrm{Y})}{\text { Distance travelled by the compound }(\mathrm{X})}
$$

\section{Bioassay test on brine shrimp, Artemia salina}

Brine shrimp medium (BSM) described by Panigrahi and Dallin [38] with slight modification was used. This was prepared by using $30 \mathrm{~g}$ sodium chloride; $0.3 \mathrm{~g}$ calcium chloride dehydrate; $1.6 \mathrm{~g}$ magnesium chloride hexahydrate; $0.5 \mathrm{~g}$ magnesium sulphate heptahydrate; $0.8 \mathrm{~g}$ potassium chloride; and $6.0 \mathrm{~g}$ glycine. The BSM was autoclaved at $121^{\circ} \mathrm{C}$ for $15 \mathrm{~min}$ stored in a brown colored Scott bottle.

Toxicity of each detectable BEA to brine shrimp larvae (Artemia salina L.) was determined. Dried $A$. salina eggs were hatched in BSM prepared for 24 hours at $27^{\circ} \mathrm{C}$ in a small water tank provided with the aeration from the motor. 30 mature larvae were selected and transferred into 24 -well cell culture plates by exposing it with $5 \mu \mathrm{l}$ of mycotoxin extract and sterile BSM was added until $500 \mu$ l. The test performed in triplicate for BEA extracted against BSM and methanol as a control. Numbers of dead larvae were counted in each dish after 24 hours of incubation at $27^{\circ} \mathrm{C}$. Surviving larvae were killed by freezing at $-20^{\circ} \mathrm{C}$ for 12 hours. 


\section{Statistical analysis}

The toxicity of BEA from $F$. sacchari and $F$. subglutinans on adult were studied on $A$. salina (Brine shrimp medium). One treatment was carried after 24 hours, data were subjected to analysis of variance test (95\% confidence level) using independent samples T-test mean values are presented. The mortality was recorded in the control afterward, for $\mathrm{LC}_{50}$, data were analyzed by analysis of variance T-test (Spss 20.0 version).

\section{RESULTS}

\section{Identification of $\boldsymbol{F}$. subglutinans and $\boldsymbol{F}$. sacchari}

A total of 55 different isolates grew from Fusarium Laboratory consisting of $F$. sacchari and $F$. subglutinans which was the causal agent of Pokkahboeng disease in sugarcane. Observation of pigmentation, macroscopic and microscopic characteristics were done after cultured on PDA and CLA. This media culture is mainly used for identification purposes as recommended by Leslie and coauthors [2].

The colony morphology of $F$. sacchari showed abundant mycelia growth after 7 days of incubation on PDA (Figure 1-A). In addition, the pigmentation produced in various colour from pale violet, pink, and peach (Figure 1-B). The observation on CLA, macroconidia usually had 3-septation with slightly falcate and thinwalled (Figure $2 \mathrm{~A}$ ). The apical cells curved while the basal cells were poorly developed. Microconidia with oval shape together with 1-septate mesoconidia (Figure 2, (A) and (B)) and simple polyphialides were observed on the prepared slide (Figure 3) Mesoconidia and microconidia in situ were present on CLA (Figure 4, (A) and (B)). Chlamydospores and microconidia chains were absent.

For $F$. subglutinans, the mycelia were abundantly growing on PDA whereas the pigmentations ranging from pale violet to deep violet (Figure 5). From in situ observation on CLA, macroconidia were sparsely formed, slender, and thin-walled with 3- or 4- septa (Figure 6 A). Curved apical cells and poorly developed basal foot-shaped cells were recorded. Oval shaped microconidia with 0-septate (Figure 6 B and 7 A) were found from agar plates attached to monophialides or polyphialides (Figure 7). No chlamydospores or microconidia chains were observing in CLA.

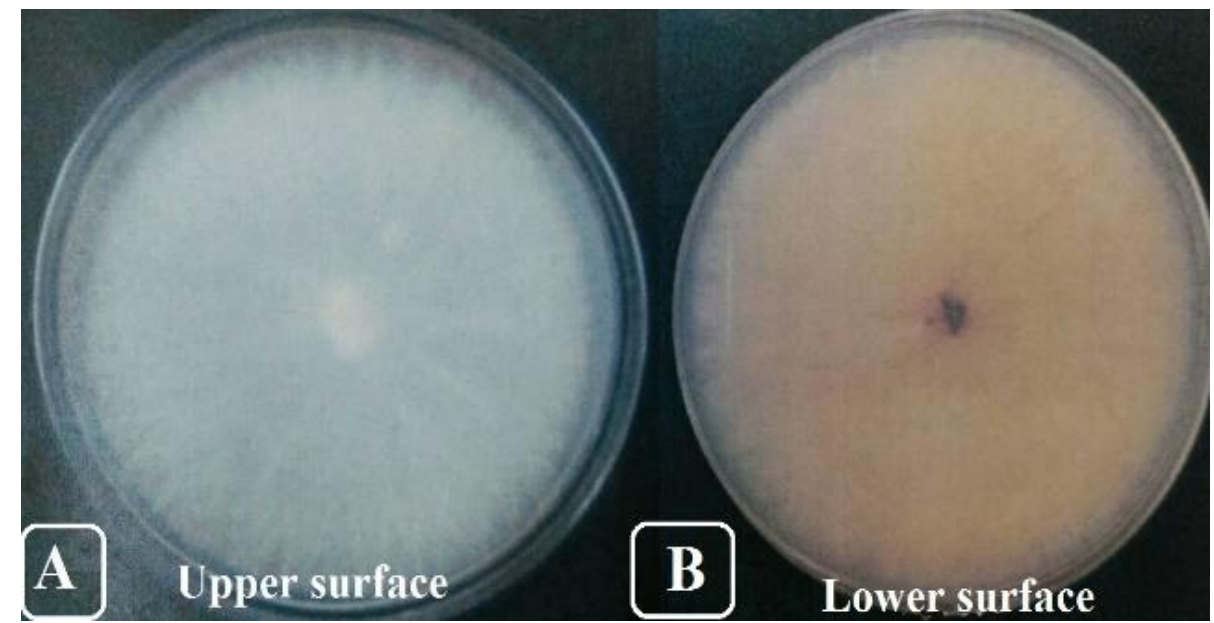

Figure 1. Colony appearance and pigmentation of Fusariumsacchari on PDA. A) Upper surface, B) lower surface. 


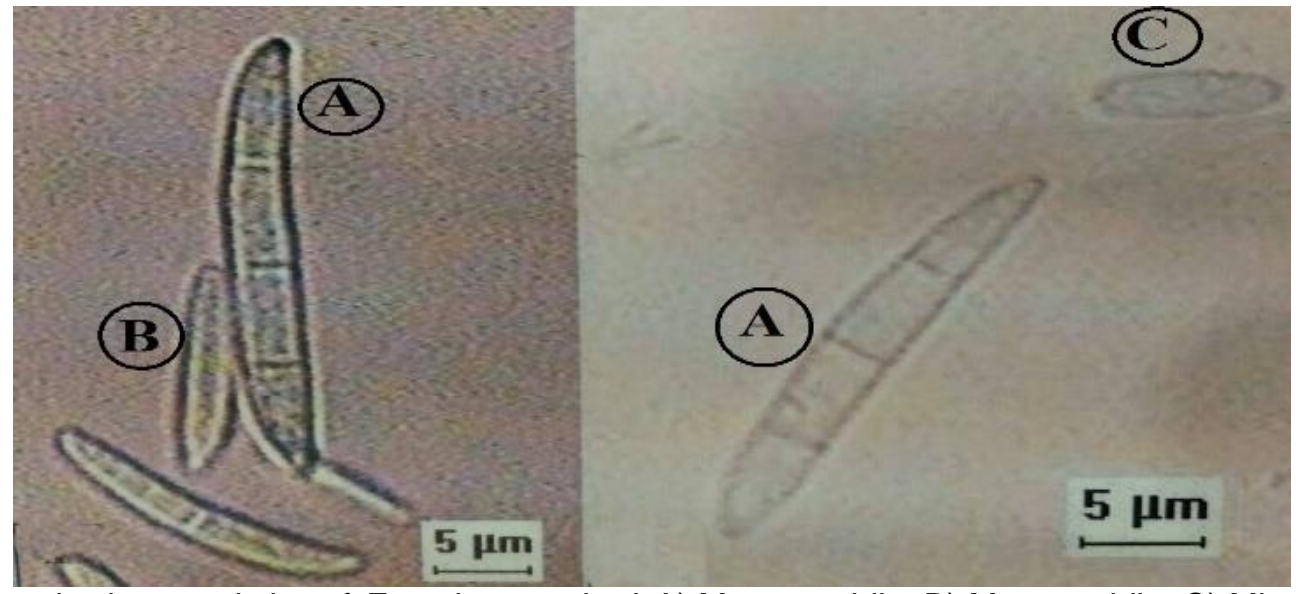

Figure 2. Microscopic characteristics of Fusariumsacchari, A) Macroconidia, B) Mesoconidia, C) Microconidia.

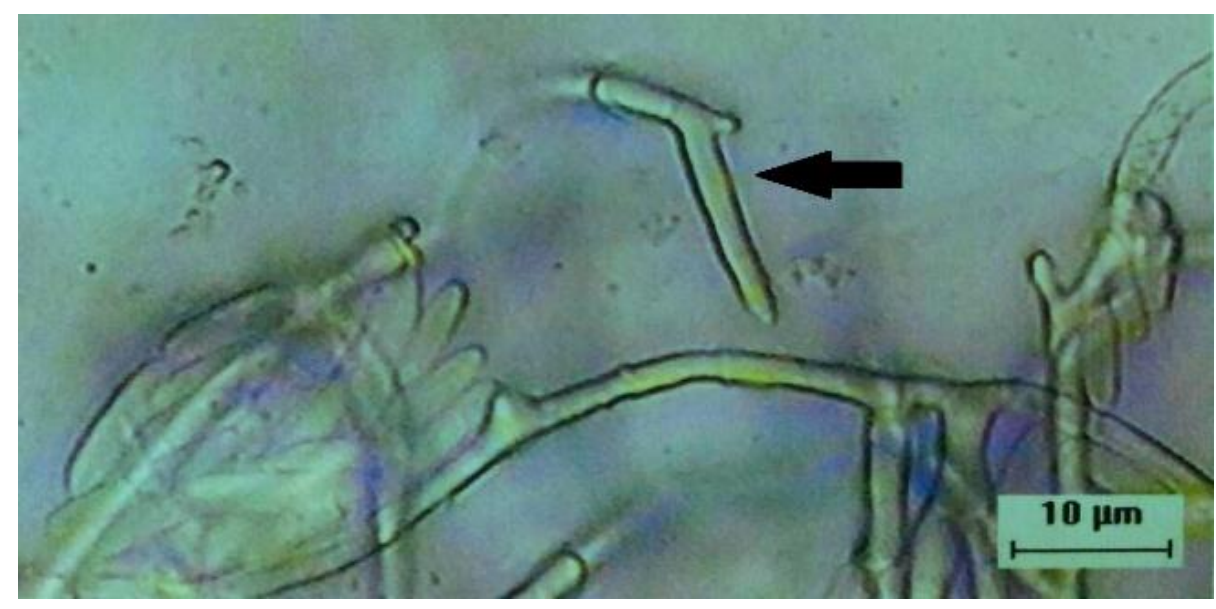

Figure 3. Simple polyphialidicconidiophores of Fusariumsacchari aerial mycelium

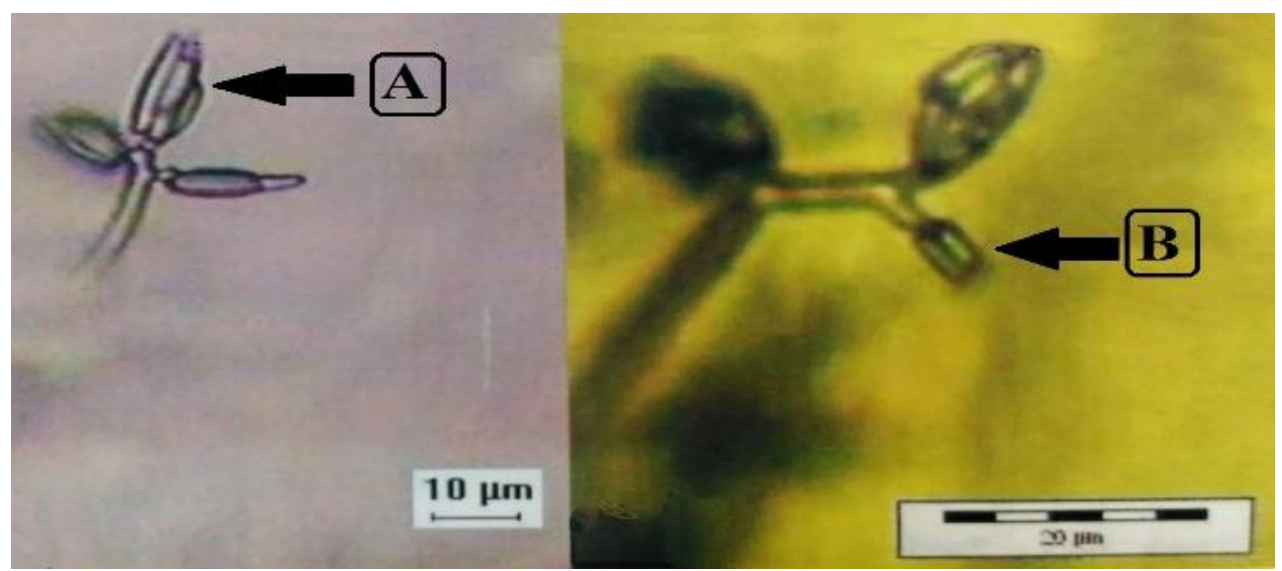

Figure 4. Polyphialides of Fusarium sacchari on CLA. A) Mesoconidia, B) Microconidia 


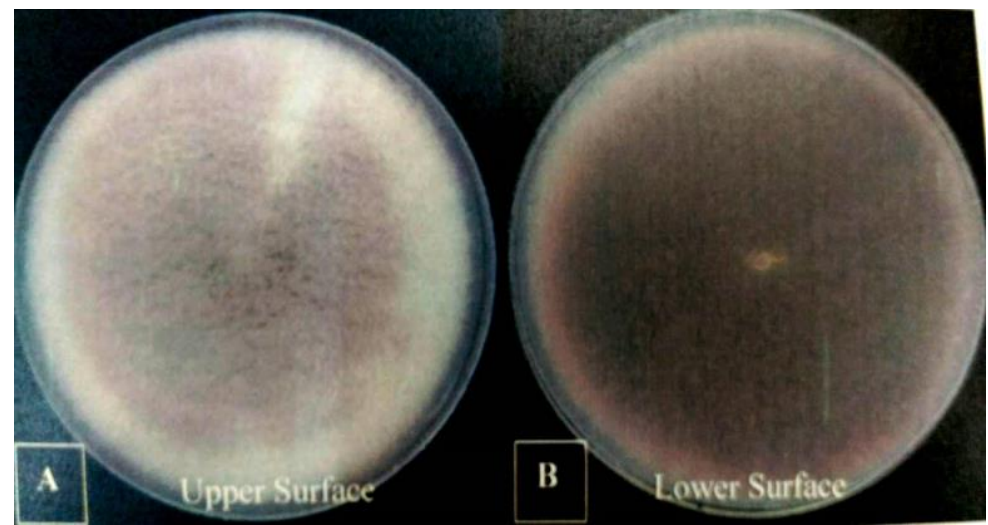

Figure 5. Colony appearance and pigmentation of Fusariumsubglutinans on PDA. A) Upper surface. B) Lower Surface.

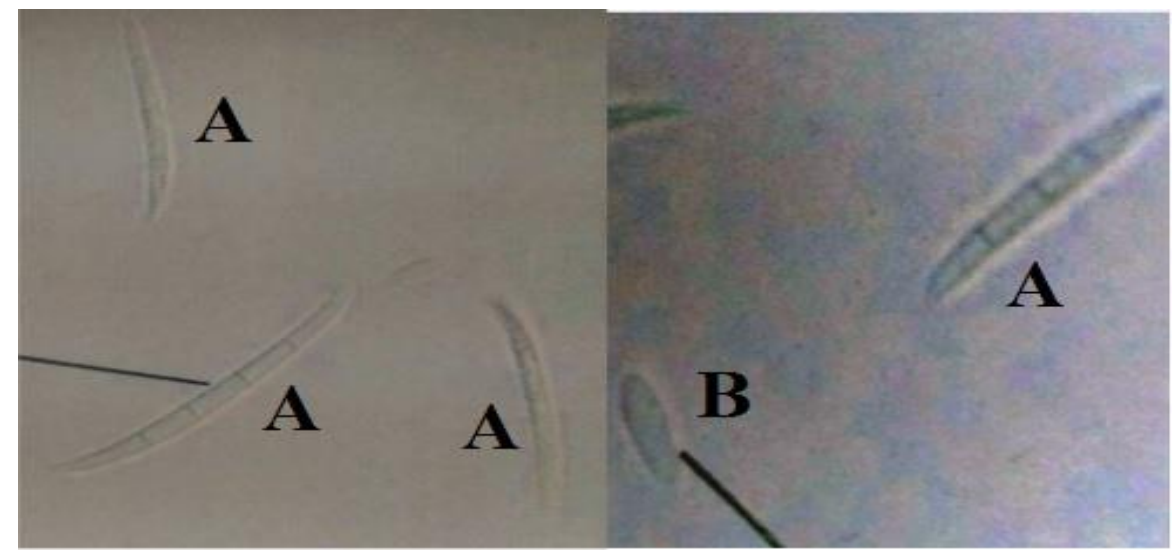

Figure 6. Microscopic characteristics of Fusariumsubglutinans, A) Macroconidia, B) Microconidia.

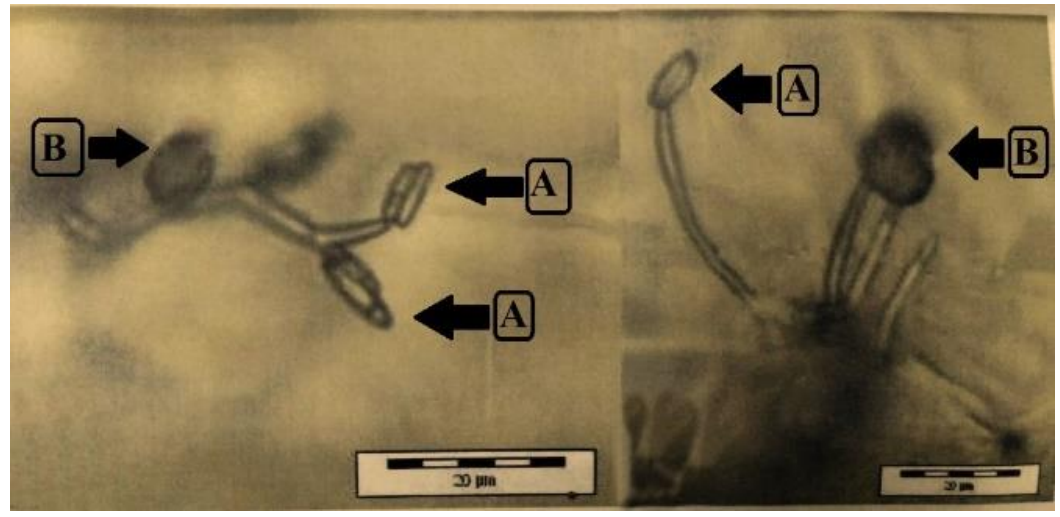

Figure 7. Polyphialides of Fusariumsubglutinans on CLA. A) Microconidia, B) False head.

\section{Detection of BEA by TLC}

BEA was extracted after 28 days of the inoculation process with $F$. sacchari and $F$. subglutinans spore suspension on corn grit cultures. The results of screening were based on the colour spot and comparison of the retention factor $\left(R_{f}\right)$ values of the samples together with the standard of BEA at a concentration of 200 ppm and further visualized under iodine vapour as shown in the Figure (8).

From Table 1, data showed that all the tested isolates of $F$. sacchari (46) and $F$. subglutinans (9) having the capable to produce BEA with the TLC method. The visualisedcolour spot of the standard with aid of iodine vapour was brown in colour and the $R_{f}$ values ranging from 0.93 till 0.97 (Mean value $=0.95$ ). Samples extracted lies almost at the same position with BEA standard colour spots were compared to verify the presence of BEA. Briefly, all isolates of $F$. sacchari and $F$. subglutinans showed $R_{f}$ value in reference to standard BEA. While the colour spots of all isolates appeared resemblance in terms with BEA standard but it is different in the colour intensity. The intensity of colour spots for all isolates was darker compared to the BEA standard exhibited brownish in colour. 
Table 1. Beauvericindetection of Fusarium sacchari and Fusarium subglutinans strains isolated from Pokkahboeng disease of sugarcane.

\begin{tabular}{|c|c|c|c|c|}
\hline N. & Fusarium species & Isolates & Location & BEA \\
\hline 1. & F. sacchari & K3243U & Gula Padang Terap (GPT), Kedah. & + \\
\hline 2. & & K3247U & Gula Padang Terap (GPT), Kedah. & + \\
\hline 3. & & K3249U & Gula Padang Terap (GPT), Kedah. & + \\
\hline 4. & & K3251U & Gula Padang Terap (GPT), Kedah. & + \\
\hline 5. & & K3252U & Gula Padang Terap (GPT), Kedah. & + \\
\hline 6. & & K3256U & Gula Padang Terap (GPT), Kedah. & + \\
\hline 7. & & K3257U & Gula Padang Terap (GPT), Kedah. & + \\
\hline 8. & & K3259U & Gula Padang Terap (GPT), Kedah. & + \\
\hline 9. & & K3260U & Gula Padang Terap (GPT), Kedah. & + \\
\hline 10. & & K3261U & Gula Padang Terap (GPT), Kedah. & + \\
\hline 11. & & K3266U & Gula Padang Terap (GPT), Kedah. & + \\
\hline 12. & & K3268U & Gula Padang Terap (GPT), Kedah. & + \\
\hline 13. & & K3269U & Gula Padang Terap (GPT), Kedah. & + \\
\hline 14. & & K3271U & Gula Padang Terap (GPT), Kedah. & + \\
\hline 15. & & K3272U & FeldaChunping, Perlis & + \\
\hline 16. & & K3273U & FeldaChunping, Perlis & + \\
\hline 17. & & K3275U & FeldaChunping, Perlis & + \\
\hline 18 & & K3277U & FeldaChunping, Perlis & + \\
\hline 19. & & K3282U & FeldaChunping, Perlis & + \\
\hline 20. & & K3283U & FeldaChunping, Perlis & + \\
\hline 21. & & K3284U & FeldaChunping, Perlis & + \\
\hline 22. & & K3285U & FeldaChunping, Perlis & + \\
\hline 23. & & K3287U & FeldaChunping. Perlis & + \\
\hline 24. & & K3288U & FeldaChunping, Perlis & + \\
\hline 25. & & K3290U & FeldaChunping, Perlis & + \\
\hline 26. & & K3291U & FeldaChunping, Perlis & + \\
\hline 27. & & K3296U & FeldaChunping, Perlis & + \\
\hline 28. & & K3303U & FeldaChunping, Perlis & + \\
\hline 29. & & K3304U & FeldaChunping, Perlis & + \\
\hline 30. & & K3305U & FeldaChunping, Perlis & + \\
\hline 31. & & K3306U & FeldaChunping, Perlis & + \\
\hline 32. & & K3307U & Jelutong, Penang. & + \\
\hline 33. & & K3309U & Kupang, Kedah. & + \\
\hline 34. & & K3311U & Kupang, Kedah. & + \\
\hline 35. & & K3312U & Kupang, Kedah. & + \\
\hline 36. & & D3325U & Rantau Panjang, Kelantan. & + \\
\hline 37. & & D3326U & Rantau Panjang, Kelantan. & + \\
\hline 38. & & D3327U & Rantau Panjang, Kelantan. & + \\
\hline 39. & & T3332U & Sri Langkap, Terengganu. & + \\
\hline 40. & & T3334U & Setiu, Terengganu. & + \\
\hline 41. & & C3338U & KampungAwah, Pahang. & + \\
\hline 42. & & C3339U & KampungAwah, Pahang. & + \\
\hline 43. & & K3350U & Baling, Kedah. & + \\
\hline 44. & & K3352U & Baling, Kedah. & + \\
\hline 45. & & K3354U & Alor Star, Kedah. & + \\
\hline 46. & & J3357U & Rengit, Johor Bahru. & + \\
\hline 47. & F. subglutinans & K3258U & Gula Padang Terap (GPT), Kedah. & + \\
\hline 48. & & K3267U & Gula Padang Terap (GPT), Kedah. & + \\
\hline 49. & & K3270U & Gula Padang Terap (GPT), Kedah. & + \\
\hline 50. & & K3293U & FeldaChunping, Perlis & + \\
\hline 51. & & K3295U & FeldaChunping, Perlis & + \\
\hline 52. & & K3308U & Kupang, Kedah. & + \\
\hline 53. & & K3324U & Rantau Panjang, Kelantan. & + \\
\hline 54. & & K3349U & Kuantan, Pahang. & + \\
\hline 55. & & K3443U & Cameron Highlands, Pahang. & + \\
\hline 56. & Control & & & - \\
\hline
\end{tabular}

$+=$ detected

- = not detected

Control $=$ non-inoculated corn grit cultures 


\section{Brine shrimp bioassay}

The extracts containing BEA were used to evaluate the toxicity of BEA towards $A$. salina (Brine shrimp larvae). Two species of the Fusarium in section Liseolais known as $F$. sacchari and $F$. subglutinans exhibited a mortality rate up to $100 \%$. Yet each of the isolates of $F$. sacchari and $F$. subglutinans was observed to show different mortality rate on $A$. salina larvae. The results tabulated in Table 2 with the toxicity level indication [39]. All the toxicity levels exhibited varying results ranging from slightly toxic to highly toxic. The calculated $t$ (1.86) was larger than tabulated $t_{0.05}(1.65)$. In conclusion, the toxicity of BEA extracts from $F$. subglutinans was more in comparison to the toxicity of BEA extracts from $F$. sacchari.

BEA toxicity towards brine shrimp larvae was highly variable. In $F$. sacchari alone, the mortality rates of brine shrimp towards extracts containing BEA was ranging from $15.56 \%$ to $100 \%$ as shown in Table 2 . The distribution in scale from slightly toxic to very toxic was 5 isolates in the slightly toxic group, 20 isolates in the toxic group, and 21 isolates in the very toxic group. Among those in a very toxic group, 9 isolates showed a $100 \%$ mortality rate on brine shrimp larvae.

While BEA extracted from corn grits inoculated with $F$. subglutinans had a mortality rate in between $66.67-100 \%$. The K3324U isolate of $F$. subglutinans showed $100 \%$ mortality for brine shrimp larvae. Narrow variations in extracts containing BEA extracted from $F$. subglutinans were more consistent in the BEA production.

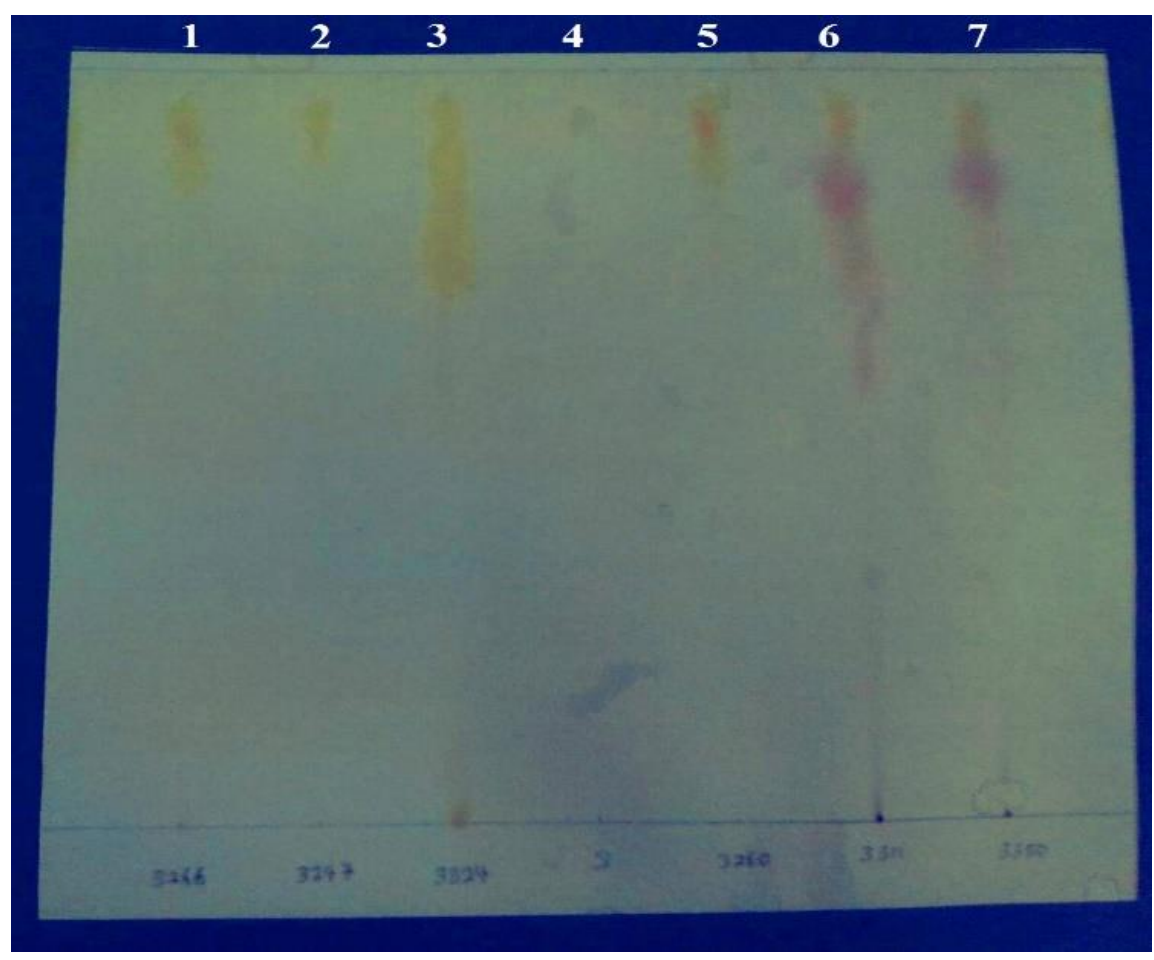

Figure 8. Thin layer chromatograms of Beauvericin developed in acetic acid; methanol: water (100:5:1) solvent system. Brown colour spots on silica gel sheet of Beauvericin standard and samples after visualization under iodine vapour. (Lane 1: K3266U, Lane 2: K3247U; Lane 3: K3324U, Lane 4: standard Beauvericin, Lane 5: K3260U, Lane 6: K3311U and Lane 7: K3350U. 
Table 2. Beauvericindetection of Fusarium sacchari and Fusarium subglutinans strains isolated from Pokkahboeng disease of sugarcane.

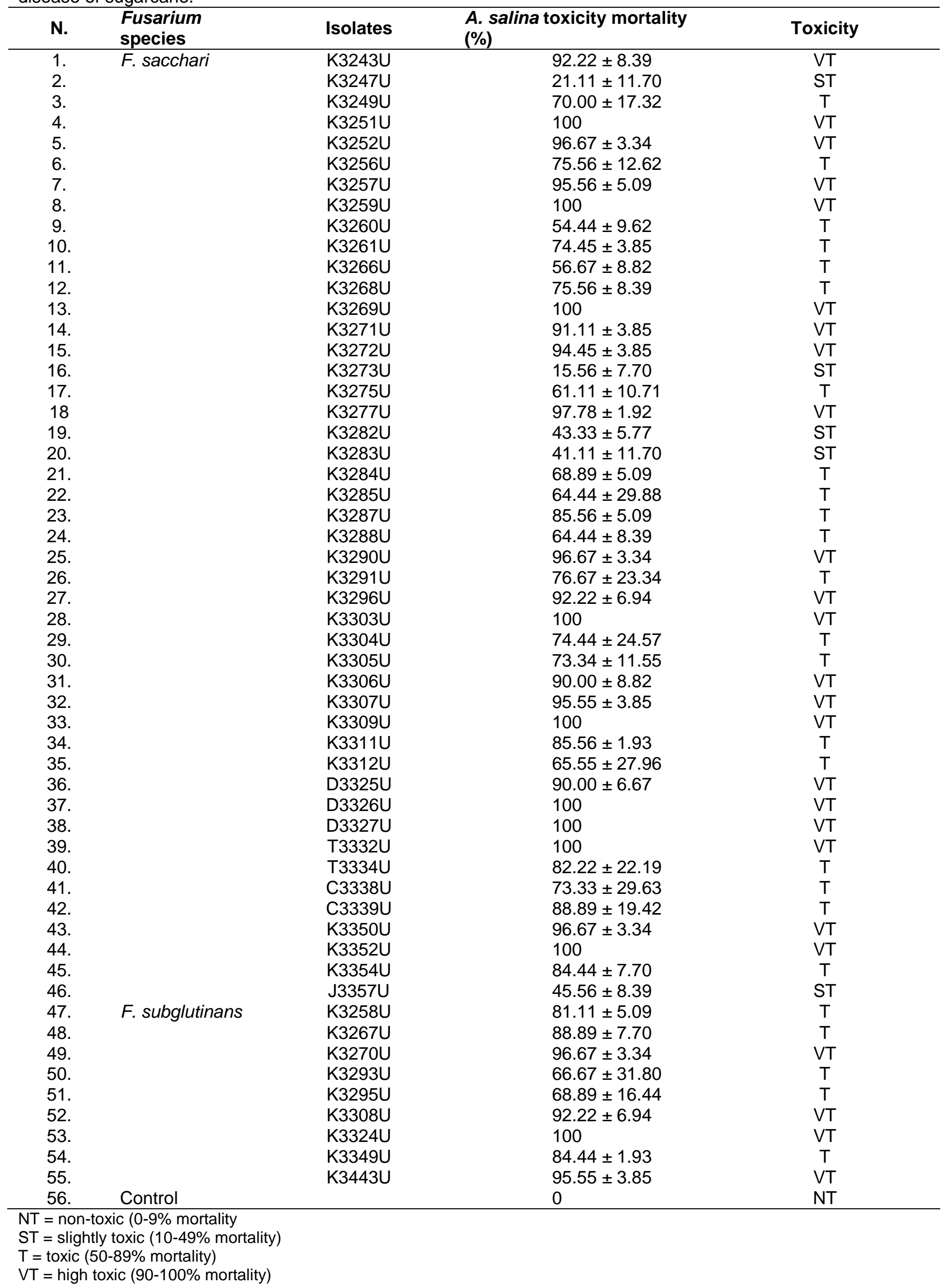




\section{DISCUSSION}

The media PDA and CLA were used instead of others as these media allowed pigmentation of Fusarium and the production of conidia for identification purposes. Fisher and coauthors [32] reported that CLA is a natural substrate medium that promoted sporulation rather than mycelia growth. Microconidia chains, false heads, polyphialides, monophialides, chlamydospores, and sporodochia can be seen in situ if these structures are present. The results showed no difference between $F$. sacchariand $F$. subglutinansin producing microconidia, and shape of macroconidia. Morphological characteristics are possible to discriminate into the two species based on the presence of mesoconidia. The distinguishable trait in producing of mesoconidia showed the ability of $F$. sacchari in producing a higher number of mesoconidia compared with $F$. subglutinans in situ on CLA media.

Interestingly, the results showed the ability of $F$. sacchari and $F$. subglutinans to produce BEA by using the TLC method. At detectable levels on the TLC method after visualization under iodine vapour. They assumed the mycotoxin profile of $F$. sacchari similar to those of $F$. subglutinans[2]. Therefore, this assumption was well supported in this study. BEA is a nonpolar cyclodepsipeptide compound as it gives high $R f$ value due to weak interaction with the polar adsorbent on the TLC plate [40]. The $R_{f}$ value 0.95 detected in the experiment of BEA was in agreement with previous studies with minor changes in $R_{f}$ value due to the diverse developing solvent system. The solvent system made up of methanol, water, and formic acid $(30: 45: 25)$ showed the $R f$ value of $B E A=0.90$ [41]. While, the $B E A R_{f}$ value under the solvent system of 1-butanol, water, and acetic acid (12:5:3) was 0.92 [40]. The results showed slight dissimilarity in BEA $R_{f}$ value compared with the previous studies due to the different solvent systems. The difference in the $R_{f}$ value might be due to several factors including the amount of material spotted, temperature, solvent system, and chemical nature of absorbent. The condition of temperature, the equilibrium between liquids and vapour in tank, sample impurities are the key to a high range of $R_{f}$ value [42-44]. In addition, the results showed a difference in intensity of colour spots between BEA that extracted from all isolates and BEA standards. The darker brown colour denoted a higher concentration for BEA which was more than $200 \mathrm{ppm}$ contained in the sample extraction [45].

However, the crude extracts for all $F$. sacchari isolates in this study tested positive for the production of BEA. Moretti and coauthors [25] detected the ability of $F$. sacchari to produce BEA. Petrovic and coauthors [46] mentioned about $F$. sacchari produced BEA and a plant pathogen for sugarcane and other crops. $F$. subglutinans is considered the producer for BEA. This study showed the ability of all tropical isolates of $F$. subglutinans for producing BEA. Moretti and coauthors [24], Moretti and caouthors [47], and ReyesVelázquez and coauthors [48] found some isolates of $F$. subglutinans of different geographic areas could not produce BEA. Several Fusarium sp. produced a BEA toxin including F. verticillioides, $F$. oxysporum, $F$. poae, F. redolens, F. proliferatum, and $F$. subglutinans $[20,35,48-51]$.

On the other hand, the result of a biotoxicity assay for the biological activity could provide the detection of either known or unknown mycotoxin in foodstuffs and useful for verification about the toxin presence after screened through chemical means. Hamill and coauthors [52] further confirmed brine shrimp as a sensitive organism towards BEA, so it was selected as the targeted organism in this bioassay test for this study. The study was focus on the mortality rate of brine shrimp towards BEA that calculated to determine the toxicity of BEA. Bioassay test confirmed by many certain studies including Logriecoand coauthors[53], Moretti and caouthors[24], and Moretti and coauthors[25], that calculated the mortality rate of brine shrimp to resolve the toxicity of mycotoxins. Indeed, BEA of $F$. sacchari and $F$. subglutinans showed a toxicity for the brine shrimp in the different levels among the same species. Two species of Fusarium in this study is shown three levels of toxicity. Butt and Goettel[54] reported the role of fungal toxins causing death for the host tissue by the combination of colonizing of fungal with nutrient depletion and the action of toxins from fungal. The toxicity BEA levels of $F$. sacchari included $46 \%$ high toxic, $43 \%$ toxic, and $11 \%$ slightly toxic of isolates. As well, the BEA toxicity of $F$. subglutinans appeared two groups included $44 \%$ high toxicity, and $56 \%$ toxic of isolates. The difference in the production BEA among the same species of Fusarium could occur in the wild population of Fusarium spp. because it may have happened a mutation. The change in production of mycotoxins resulted from the effect of a mutation on plant pathogens [55].The mutation in the Fusarium isolates may occur as a result of several factors; (1) the interaction between Fusarium and the host plant such as influence of plant defences,(2) the blend in mating occurred among avirulence and high virulence (56),(3) the type of nutrient, the preservation conditions, and the length of preservation time. 


\section{CONCLUSION}

The difference in toxicity for the brine shrimp reflected the difference in the capability of Fusarium isolates to cause the pathogenicity. This study manifests the capability of both $F$. sacchari and $F$. subglutinans to produce effective BEA. Therefore, BEA may play a big role in the occurrence of the infection for the host plant by causing the toxicity for the host tissues and can be a potential pathogenicity factor.

Funding: This research received no external funding

Acknowledgements: The authors thank for school of biology science - UniversitiSains Malaysia and Prof. BaharuddinSalleh for funding and allowing for doing the experiments in his lab (Fusarium lab 107).

Ethical approval: All applicable international, national, and/or institutional guidelines for the care and use of animals were followed.

Informed consent: Additional informed consent was obtained from all individual participants for whom identifying information is included in this article.

Conflict of Interest: All authors certify that they have no affiliations with or involvement in any organization or entity with any financial interest.

\section{REFERENCES}

1. Bower R, Birch RG. Transgenic Sugarcane Plants via Microprojectile Bombardment. Plant J. 1992 May ;2:409-16.

2. Leslie JF, Summerell BA. The Fusarium Laboratory Manual. UK: Blackwell Publishing Ltd; 2006, 388 p..

3. Desjardins AE. Fusarium mycotoxins: chemistry, genetics, and biology. St Paul, Minnesota; 2006. 260 p..

4. Al-Ani LKT, Franzinoc T, Aguilar-Marcelinod L, HaicharcFeZ, Furtadoe EL, Razaf W, Jatoig GH, Raza M. The role of microbial signals in plant growth and development: Current status and future prospects. In: Rastegari AA, Yadav AN, Awasthi AK, Yadav N (Eds.), New and Future Developments in Microbial Biotechnology and Bioengineering. Elsevier, USA, 2020 a; pp. 225-42.

5. Matny $\mathrm{O}$, Khalifah $\mathrm{MH}$. Biological control of crown rot disease caused by Fusarium graminearum on wheat in Iraq. The Iraqi Journal of Agricultural Sciences, 2015Jan;46(6):984-97. doi: 10.13140/RG.2.2.35239.65445

6. Desjardins AE, Proctor RH. Molecular biology of Fusarium mycotoxins. Int. J. Food Microbiol. 2007 Oct;119:47-50.

7. Jestoi M. Emerging Fusarium-mycotoxins fusaproliferin, beauvericin, enniatins, and moniliformin-a review. Crit Rev Food Sci Nutr. 2008Jan ;48:21-49. doi: 10.1080/10408390601062021.

8. Attitalla IH, Al-Ani LKT, Nasib MA, Balal IAA, Zakaria M, El-Maraghy SSM, Karim SMR. Screening of Fungi Associated With Commercial Grains and Animal Feeds in Al-Bayda Governorate, Libya. World Appl. Sci. 2010 a Jan;9(7):746-56.

9. Attitalla IH, Mansour SE, Mohamed WS, Al-Ani LKT, Mohammed AM, Faturi MY, Balal IAA, El-Maraghy SSM. Influence of Aspergillus Flavus and Aspergillus Terreus on the protein value of the two varieties of peanut grains. International Mycotoxin ConferenceMycoRed 2010, Penang-Malaysia, Universiti Sains Malaysia, School of Biology Science, 1-4 Dec; 2010 b. p.177.

10.Li C, Zuo C, Deng G, Kuang R, Yang Q, Hu C, Sheng O, Zhang S, Ma L, Wei Y, Yang J, Liu S, Biswas MK, Viljon A, Yi G. Contamination of Bananas with Beauvericin and Fusaric Acid Produced by Fusarium oxysporum f. sp. cubense. PLoS ONE. 2013 Jul ;8(7):e70226. doi:10.1371/journal.pone.0070226.

11.Al-Ani LKT, Yonus MI, Mahdii BA, Omer MA, Taher JK, Albaayit SFA, Al-Khoja SB. First record of use Fusarium proliferatum fungi in direct treatment to control the adult of wheat flour Triboliumconfusum, as well as, use the entomopathogenic fungi Beauveriabassiana. Ecol Environ Conserv. 2018 Sep ;24(3):29-34.

12.Josephs RD, Krska R, Schuhmacher R, Grasserbauer M. A rapid method for the determination of the Fusarium mycotoxin beauvericin in maize. Fresenius J Anal Chem. 1999 Jan ;363(1):130-31.

13.Grove JF, Pople M. The insecticidal activity of beauvericin and the enniatin complex. Mycopathologia. 1980 Jan;70(2): 103-05. doi:https://doi.org/10.100 7/BF00443075.

14.Xu Y, Orozco R, Wijeratne EM, Gunatilaka AA, Stock SP, Molnár I. Biosynthesis of the cyclooligomerdepsipeptidebeauvericin, a virulence factor of the entomopathogenic fungus Beauveriabassiana. Chem Biol. 2008 Sep;15:898-907.

15.Gupta S, Krasnoff SB, Underwood NL, Renwick JAA, Roberts DW. Isolation of beauvericin as an insect toxin from Fusarium semitectum and Fusarium moniliforme var. subglutinans. Mycopathologia. $1991 \mathrm{Sep} ; 115(3): 185-89$.

16. Meca G, Sospedra I, Soriano JM, Ritieni A, Moretti A, Manes J. Antibacterial effect of the bioactive compound beauvericin produced by Fusarium proliferatumsolid medium of wheat. Toxicon. 2010 Sep;56(3):349-54. doi:10.1016/j.toxicon.2010.03.022. 
17.Calò L, Fornelli F, Ramires R, Nenna S, Tursi A, Caiaffa MF, Macchia L. Cytotoxic effects of the mycotoxin beauvericin to human cell lines of myeloid origin. Pharmacol. Res. 2004 Jan ;49:73-7.

18. Lin L, Zhang J, Wang P, Wang Y, Chen J. Thin-layer chromatography of mycotoxins and comparison with other chromatographic methods. J. Chromatogr.A. 1998 Jul ;815(1):3-20.

19.Gilbert J, Anklam E. Validation of analytical methods for determining mycotoxins in foodstuffs. Trends Anal. Chem. 2002 Jun ;21:468-86.

20.Tuiche MV, Lopes AA, Silva DB, Lopes NP, Pupo MT. Direct MALDI-TOF/TOF analyses of unnatural beauvericins produced by the endophytic fungus Fusarium oxysporum SS46. Rev. Bras. Farmacogn. 2014 Jul-Aug ;24:433-38. doi:http://dx.doi.org/10.1016/j.bjp.201 4.06.002.

21.Jajic I, Dudaš T, Krstovic S, Krska R, Sulyok M, Bagi F, Savic Z, Guljaš D, Stankov A. Emerging fusarium mycotoxins fusaproliferin, beauvericin, enniatins, and moniliformin in serbian maize. Toxins. 2019 Jun ; 11:357. doi:10.3390/toxins11060357.

22.Pittet A. Modern methods and trends in mycotoxin analysis. Mitt. Lebensmittelunters. Hyg. 2005 Sep ; 96: 424-44.

23. Watson DH, Lindsay DG. A critical review of biological methods for the detection of fungal toxins in food and foodstuff. J. Sci. Food Agric. 1982 Jan ; 33:59-67.

24. Moretti A, Logrieco A, Bottalico A, Ritieni A, Randazzo G, Corda P. Beauvericin production by Fusarium subglutinans from different geographical areas. Mycol. Res. 1995 Mar ; 99(3): 282-86. doi:10.1016/S09537562(09)80899-X.

25. Moretti A, Mulè G, Ritieni A, Logrieco A. Further data on the production of beauvericin, enniatins and fusaproliferin and toxicity to Artemia salina by Fusarium species of Gibberellafujikuroi species complex. Int J Food Microbiol. 2007 Sep;118:158-63.

26. SitiNordahliawate MS. Pathogenicity and etiology of Fusarium species associated with Pokkahboeng disease on sugarcane. Msc Thesis, Pulau Pinang, UniversitiSains Malaysia. 2007;135 p.

27. Booth C. The Genus Fusarium. Kew, Surrey, England: Commonwealth Mycological Institute, 1977; 237 p.

28.Gerlach W, Nirenberg H. The genus Fusarium - A pictorial atlas. Mitteilungenaus der BiologischenBundesanstaltFür Land- und Forstwirtschaft (Berlin - Dahlem). 1982; 209: 1-405.

29. Nelson PE, Toussoun TA, Marasas WFO. Fusarium Species: An Illustrated Manual for Identification. University Park, Pennsylvania: Pennsylvania State University Press. 1983; 193 p.

30.Burgess LW, Summerell BA, Bullock S, Gott KP, Backhouse LW. Laboratory Manual for Fusarium Research, 3rd (ed.), Sydney, Australia, University of Sydney, Royal Botanic Gardens,. 1994;134 p.

31. Wijayawardene NN, Hyde KD, Al-Ani LKT, Tedersoo L, et al. Outline of Fungi and fungi-like taxa. Mycosphere, 2020 Apr; 11(1):1060-456. doi: 10.5943/mycosphere/11/1/8.

32.Fisher NL, Burgess LW, Toussoun TA, Nelson PE. Carnation leaves as a substrate and for preserving cultures of Fusarium species. Phytopathology. 1982 Jan ; 72:151-53.

33. Kornerup A, Wancher JH. Methuen handbook of color. 3rd ed. London: Eyre Methuen Ltd. 1978; 252 p.

34. Logrieco A, Doko MB, Moretti A, Frisullo S, Visconti A. Occurrence of fumonisin B1 and B2 in Fusarium proliferatum infected Asparagus plants. J. Agric. Food Chem. 1998 Nov; 46: 5201-204.

35.Song H-K, Ahn JH, Yoong HL, Mohan L. Analysis of beauvericin and unusual enniatins co-produced by Fusarium oxysporum FB1501(KFCC11363P). ). J. Microbiol Biotechnol. 2006 Jul; 16:1111-119.

36. Touchstone JC. Practice of Thin Layer Chromatography. $3^{\text {rd }}$ ed. USA, John Wiley and Sons, Inc. 1992; p. 1-14.

37. Fessenden RJ, Fessenden JS, Feist P. Organic Laboratory Techniques.Brooks/Cole Thomson Leaning, Inc, USA, Cengage Learning, 2001; p. 133-138.

38.Panigrahi S, Dallin S. Toxicity of the Alternariaspp metabolites, tenuazonic acid, alternariol, altertoxin-I, and alternariol monomethyl ether to brine shrimp - (Artemia salina L) larvae. J. Sci. Food Agric. 1994 Dec; 66: 493-96.

39. Harwig J, Scott PM. Brine shrimp (Artemia salina L.) larvae as a screening system for fungal toxins. Appl. Microbiol., 1971 Jun; 21:1011-016.

40.Asraff A, Rojas CG, Torre MDI. Isolation of dipicolinic acid as an insecticidal toxin from Paecilomycesfumosoroseus. Appl Microbiol Biotechnol. 2005 Feb; 68:542-47.

41. Champlin FR, Grula EA. Noninvolvement of beauvericin in the entomopathogenicity of Beauveriabassiana. Appl. Environ. Microbial. 1979 Jun; 37(6): 1122-126.

42. Hais JM. Factors which influence paper chromatographic $R_{F}$ values: Introductory remarks. J. of Chromatography A. 1968 Nov; 33:25-27.

43. Karunyavanij S. Factors affecting the TLC of aflatoxins analysis. In: Semple RL, Frio AS, Hicks PA, Lozare JV, (Eds). Mycotoxin prevention and control in foodgrains. Bankok, Thailand, Food and Agriculture Organisation. 1991; p.96-109. 
44.Nash JJ, Meyer JA, Everson B. What factors affect the separation of substances using thin-layer chromatography? An undergraduate experiment. J. Chem. Educ.. 2001 Mar; 78:364-65. doi:10.1021/ed078p364.

45. Fried B, Sherma J. Thin-layer chromatography: techniques and applications. New York, Dekker, M.,1982; p. 17:308.

46. Petrovic T, Burgess LW, Cowie I, Warren RA, Harvey PR. Diversity and fertility of Fusarium sacchari from wild rice (Oryzaaustraliensis) in Northern Australia, and pathogenicity tests with wild rice, rice, sorghum and maize. Eur $\mathrm{J}$ Plant Pathol. 2013 Apr; 136:773-788.

47. Moretti A, Mule G, Ritieni A, Laday M, Stubnya V, Hornok L, Logrieco A. Cryptic subspecies and beauvericin production by Fusarium subglutinans from Europe. Int J Food Microbiol. 2008 Aug; 127: 312-315. doi:10.1016/j.ijfoodmicro.2008.08.003.

48. Reyes-Velázquez WP, Figueroa-Gómez RM, Barberis M, Reynoso MM, Rojo FG, Chulze SN, Torres AM. Fusarium species (section Liseola) occurrence and natural incidence of beauvericin, fusaproliferin and fumonisins in maize hybrids harvested in Mexico. Mycotoxin Res. 2011 May; 27(3):187-94. doi: 10.1007/s12550-011-0095-6.

49. Frisvad JC, Thrane U, Samson RA, Pitt JI. Important mycotoxins and the fungi which produce them. In: Hocking AD, Pit JI, Samson RA, Thrane U. (Eds.), Advances in Food Mycology. New York, USA, Springer, 2006; p. 3-31.

50.Somma S, Alvarez C, Ricci V, Ferracane L, Ritieni A, Logrieco A, Moretti A. Trichothecene and beauvericin mycotoxin production and genetic variability in Fusarium poae isolated from wheat kernels from northern Italy. Food Addit Contam: Part A. 2010 Dec; 27(5):729-37. doi:10.1080/ 19440040903571788.

51.Xu L, Wang J, Zhao J, Li P, Shan T, Li X, Zhou L. Beauvericin from the endophytic fungus, Fusarium redolens, isolated from Dioscoreazingiberensis and its antibacterial activity. Nat. Prod. Commun. 2010 May; 5(5):811-14. doi:10.1016/j.jbiotec.2008.07.304.

52. Hamill RL, Higgens CE, Boaz HE, Gorman M. The structure of beauvericin, a new depsipeptide antibiotic toxic to Artemia salina. Tet. Letters. 1969 Aug; 49:4255-258.

53. Logrieco A, Moretti A, Bottalico A, Corda P. Occurrence and toxigenicity of Fusarium proliferatum from preharvest maize ear rot, and associated mycotoxins, in Italy. Plant Dis. 1995 Dec; 79(7):727-31. doi:10.1094/PD-79-0727.

54.Butt TM, Goettel MS. Bioassays of Entomogenous Fungi. In: Navon A, Ascher KRS (Eds), Bioassays of entomopathogenic microbes and nematodes. UK, CAB International, 2000; p.141-195.

55.Qiu J, Shi J. Genetic Relationships, Carbendazim Sensitivity and Mycotoxin Production of the Fusariumgraminearum Populations from Maize, Wheat and Rice in Eastern China. Toxins. 2014 Jun; 6(8): 2291309. Doi: https://www.mdpi.com/2072-6651/6/8/2291.

56. Al-Ani LKT, Furtado EL. The effect of incompatible plant pathogen on the host plant. In: Sharma V, Salwan R, AlAni LKT (Eds.), Molecular Aspects of Plant Beneficial Microbes in Agriculture. USA, Cambridge, Elsevier Science, 2020 b; p.47-57.

(C) 2021 by the authors. Submitted for possible open access publication under the terms and conditions of the Creative Commons Attribution (CC BY NC) license (https://creativecommons.org/licenses/by-nc/4.0/). 